\title{
ANÁLISE SEMIÓTICA DE TEXTOS LITERÁRIOS COM O FIM NA SALA DE AULA
}

Rosane Reis de Oliveira (UERJ)

Resumo: Este artigo relata minhas experiências acadêmicas com Darcilia Simões desde que, como minha orientadora, apresentou-me à Semiótica. Abordo como o estudo da Teoria da Iconicidade Verbal de Simões contribui para que as aulas de gramática, estudo do léxico e interpretação de texto sejam mais significativas para os alunos, sem, no entanto, enchê-los de nomenclaturas e teorias exaustivas e desnecessárias. A semiótica, com foco na Teoria da Iconicidade Verbal, portanto, tornou-se cerne de minha pesquisa em linguagem verbal e não verbal, usadas na aplicação e sistematização das potencialidades do signo. No artigo, relato algumas de minhas investigações no campo semiótico, apresentando alguns modelos de análise dos textos literários com o fim na sala de aula do ensino médio.

Palavras-chave: Iconicidade. Semiótica. Ensino.

Abstract: This article recounts my academic experiences with Darcilia Simões since, as my academic advisor, she introduced me to Semiotics. I approach how the study of Simões Theory of Verbal Iconicity contributes to the practice of grammar, lexicon study and interpretation being more meaningful to students, without, however, filling them with exhaustive and unnecessary nomenclatures and theories. Semiotics, focusing on the Theory of Verbal Iconicity, therefore, became the core of my research in verbal and nonverbal language, used in the application and systematization of the potentialities of the sign. In this article, I report some of my semiotic investigations, presenting some models of analysis of literary texts with with a focus on the high school classroom.

Keywords: Iconicity. Semiotics. Teaching.

"A literatura corresponde a uma necessidade universal que deve ser satisfeita sob pena de mutilar a personalidade, porque pelo fato de dar forma aos sentimentos e à visão do mundo ela nos organiza, nos liberta do caos e portanto nos humaniza. Negar a fruição da literatura é mutilar a nossa humanidade."

Antonio Candido. 
Inicio este artigo com as palavras de Candido, porque elas me trazem à memória tempos gratificantes em que pude conviver, em sala de aula, com a professora Darcilia Simões, a quem ofereço minhas mais honestas palavras de agradecimento por ter-me apresentado a um semnúmero de práticas didáticas mais significativas para o ensino da língua materna. Hoje, para mim, é inimaginável planejar aulas de Português sem o apoio da literatura e da semiótica, por exemplo. Ambas são elos que dão sentido às práticas pedagógicas para o ensino da língua, tomando as construções literárias, as escolhas lexicais, os percursos semióticos dos textos e todas as formas de uso da língua em diferentes épocas e lugares como linhas e entrelinhas para o desenvolvimento da competência linguística. Sem as leituras dos livros e artigos de Darcilia, em que me aprofundei, suas aulas e orientações, talvez nem chegasse a algumas conclusões sobre o ensino da língua tampouco ao desenvolvimento de trabalhos de pesquisa na área semiótica. Se hoje meu interesse pela semiótica de extração peirceana, que não tem data recente, é cada vez mais intenso, devo isso à minha excepcional orientadora e amiga que me conduziu até aqui e, por minha pretensão e vontade, ainda me levará adiante por muito tempo, agora já como parceiras de trabalho e pesquisa. 
A semiótica, com foco na Teoria da Iconicidade Verbal (TIV), de Simões, tornou-se cerne de minha pesquisa em linguagem verbal e não verbal, usadas na aplicação e sistematização das potencialidades do signo. Minhas investigações tratam de modelos de análise semiótica dos textos literários com o fim na sala de aula do ensino médio, muito embora meu público direto não seja esse. Explico: nos últimos dois anos, venho-me dedicando a ministrar cursos e mentorias para professores de língua portuguesa na persecução de ofertar-lhes novas abordagens de práticas didáticas para o ensino de gramática, redação e interpretação de textos. Então, de certa forma, continuo na aplicação das teorias as quais pesquiso nas salas de aula do ensino básico.

Dito isso, percebo que há necessidade de se debater muito as motivações das aulas de literatura no Brasil e o desencontro com as aulas de Língua Portuguesa, muitas vezes intituladas de Gramática. Muitas perguntas permeiam meus estudos semióticos envolvendo textos literários nas aulas de Português - como assim chamam algumas instituições de ensino básico - que podem ser respondidas a partir de uma ampla visão do texto que não se encerra na abordagem comumente usada nos momentos da aula em 
que o professor caracteriza como "aula de compreensão e interpretação". Vamos aos primeiros questionamentos e ideias já desenvolvidas sobre o tema em tela.

\section{CONTRIBUIÇÕES DA LINGUÍSTICA TEXTUAL E DA PRAGMÁTICA}

Apesar da vasta contribuição da Linguística Textual e da Pragmática no último século, o ensino de Língua e Literatura, no Brasil, ainda não se definiu por completo, demonstrando ainda haver a prática pedagógica do "isolamento". Nas aulas de Língua, ensinam-se as normas gramaticais ancoradas em textos, mas ainda em pretensas práticas de linguística textual sem muito objetivo definido ou somente numa abordagem metalinguística, sem passar pelas fases linguística e epilinguística tão necessárias à apreensão da língua como forma de comunicação efetiva e eficiente; nas aulas de Literatura, ensinam-se as escolas literárias e seus representantes de maneira cronológica, sem associar, nos movimentos literários, a produção textual de cada autor e seu estilo com as abordagens linguísticas e semióticas de suas obras. Essa prática acaba gerando atividades didáticas sem sentido para os alunos, afastandoos mais do que os familiarizando com o uso produtivo da língua. Aos professores de Língua e Literatura caberia a árdua tarefa de unir os estudos dos gêneros discursivos, 
tão largamente usados em livros didáticos, aos novos conhecimentos da semântica, da estilística e da semiótica a fim de capacitar os discentes a uma real interpretação das obras literárias clássicas, com o fito de ampliar-lhes o repertório lexical e de apetrechá-los para leituras profícuas em suas vidas profissional e pessoal.

Ainda se percebe uma forte tendência em resistir às contribuições de outras correntes teóricas mais modernas, como a semiótica, por exemplo, talvez pelas fortes raízes do estudo do texto baseado na forma e nos aspectos estruturais. É inegável, contudo, que há um esforço da Academia em capacitar os docentes a conquistar uma perspectiva didática em dimensões pragmáticas. Os novos textos oficiais da Base Nacional Comum Curricular (BNCC) são prova de que a nova perspectiva do ensino da língua vem tornando mais significativa a prática didática do professor de Língua e Literatura. Disso decorre a minha preocupação em preparar os professores de língua portuguesa a ensinar linguagem aos alunos - muito mais do que somente a língua - de forma mais expressiva para que possam interagir com certa facilidade no meio social de que farão parte e, até mesmo, serem capazes de usar a língua como meio de influenciar seus interlocutores na prática social. 
Essa preocupação com a língua e seu uso adequado para certas instâncias sociais decorre de saber que a linguagem verbal é um dos meios mais eficazes de interação social. Por meio dela, expressamos pensamentos, relatamos experiências, descrevemos nossas impressões sobre o mundo. Por ser uma atividade criadora em si mesma, a língua é usada como instrumento de persuasão e de sugestão. É pela habilidade de escolher as palavras certas que muitos alcançam o sucesso, influenciam as decisões do outro, dizem o que pensam e o que sentem. A língua é, pois, o meio simbólico, articulado, produtivo, intencional e regular de o homem não só transmitir informação mas também extravasar seus estados psicológicos e afetivos. Ampliar o repertório lexical, a capacidade de interpretação pela pragmática e pela semiótica, portanto, assume, no contexto social, grande relevância. Somente pela leitura mais técnica e estudo do léxico, nossos alunos podem adquirir competências linguísticas imprescindíveis a um bom nível de interpretação, compreensão e produção textuais.

\section{A LITERATURA NOS TEXTOS DA BNCC}

A Base Nacional Curricular Comum apesar de não delimitar a Literatura como componente curricular específico apresenta o texto literário como suporte 
para o ensino de todos os segmentos e áreas. Tanto a cientificidade quanto a importância dos estudos literários permeiam todo o documento que determina o essencial para o Ensino Básico no Brasil. A Literatura se instaura, dentre as competências, no repertório cultural e propaga seu valor para a formação humana. Ao estudar obras literárias, o discente faz considerações acerca de estética, ética, ideologia e política a partir da leitura crítica.

A BNCC, buscando a formação mais complexa do educando, apresenta a necessidade de uma proposta que visa à progressão de leitura, bem como à ampliação do repertório e a sua interação com o que não pertence diretamente ao estudante, possibilitando estabelecer relações com as habilidades socioemocionais já que o texto literário permite o contato com diversos valores. Para que a leitura alcance toda a complexidade proposta, torna-se necessário um estudo sistemático de correntes teóricas mais modernas como a Semiótica e a Pragmática.

Para dar ênfase ao que afirmo sobre o ensino da língua e da literatura e a forma como devem estar ladeadas, venho propondo trabalhos com os treze minicontos sobre insônia, de Marina Colasanti, encontrados no livro Hora de alimentar serpentes (2013) e os contos de Estórias Abensonhadas de Mia Couto (2012). 


\section{SOBRE OS TREZE MINICONTOS "HISTÓRIA DE INSÔNIA"}

Os minicontos sobre a insônia, de Colasanti, estão espalhados pelo livro, intercalando várias outras narrativas, o que é bastante significativo e já pode nos conduzir a uma interpretação baseada em uma das maiores metáforas da obra. Logo no prólogo, Marina Colasanti faz escolhas lexicais que nos permitem antever toda a significação pretendida pela autora na junção dos minicontos, aparentemente isolados, soltos e sem conexão. Diz assim a autora no prólogo: "Enfiou a serpente na agulha. E começou a costurar." A escolha do vocábulo "serpente" já remete o leitor a um novelo sibilante, enfiado na agulha, mostrando, de início, a linha metafórica do livro: a serpente é a linha com que se vão costurar as micronarrativas separadas pelas folhas de papel como uma colcha de retalhos. Também a estrutura sintática das orações do pequeno prólogo e a pontuação nos remetem à ideia de recorte, dois tecidos que, embora separados, podem-se unir como dois retalhos costurados: a conjunção coordenativa aditiva "e", que, iconicamente, marca o período composto por coordenação, aparece, nessa construção, desligada da oração anterior. O ponto entre as duas orações representa, no prólogo, a metáfora do ponto de bordado na costura, ou seja, a possibilidade 
da união. Fica claro que, cabe ao leitor, fazer essa costura entre as várias histórias. A autora nos apresenta, nesses minicontos da insônia, o hábito centenário de contar carneiros com várias leituras possíveis, utilizando-se de figuras de linguagem ricas em possibilidades interpretativas; intertextualidades diversas; pistas indiciais e icônicas responsáveis pela coerência tanto interna quanto externa dos contos; escolhas lexicais como mecanismos linguísticos de significação precisa da palavra dentro de seu contexto, com o objetivo de envolver o leitor na atmosfera insólita dos minicontos, desenhando todo o percurso semióticopragmático que envolve muito mais o modo como se diz do que, propriamente, o que se diz. Nessas treze histórias de insônia, espalhadas pelo livro e intercaladas por outras micronarrativas, há referência cultural a um costume antigo de contar carneiros que, de acordo com a história, foi recriado a partir de um conto árabe do século XII, na obra Dom Quixote. No século XVII a história ganha a Europa e mais tarde o mundo. De forma intertextual, a autora une essa prática cultural com as figuras icônicas do lobo e do cordeiro das histórias infantis a uma famosa parábola bíblica do lobo em pele de cordeiro. Gradualmente, em cada história de insônia, ela vai subvertendo as simbologias criadas em torno dos personagens, parodiando trechos dos 
contos infantis e dialogando com outras narrativas. Toda essa possibilidade de leituras interpretativas pode ser demonstrada aos alunos por meio de um levantamento de vocabulário de cada conto, apontando as escolhas lexicais e os campos semânticos subjacentes da relação entre o real e o insólito, o fato e a quebra de expectativa, a similaridade e a subversão.

A base da minha atual pesquisa está nos minicontos sobre a insônia que fazem parte da obra Hora de alimentar as serpentes, no entanto não só nessa obra, mas em toda a sua adorável literatura, Marina Colasanti é conhecida por sua forma delicada de fazer reflexões acerca de assuntos pouco confortáveis. As histórias de insônia, por exemplo, retomam elementos da Idade Média e da mitologia de diversos povos através de seu equilíbrio narrativo.

A escolha do gênero aproxima a construção da autora à profissão de ourives, palavras da própria autora, já que o miniconto apresenta, em suas características, intensidade e tensão que se desdobram em diversos ecos permeados de metáforas, metonímias, intertextualidades, simbologias, multiplicidade de perspectivas e elipses que serão tecidas a partir do repertório sociocultural e linguístico do leitor.

A própria autora diz que o mergulho mais profundo será dado de acordo com o tamanho da "mochila cultural" que 
o leitor carrega já que os contos fazem alusão à memória coletiva. Isso ocorre, principalmente, quando nos apresenta como personagens das histórias de insônia o lobo e o carneiro, mas ressignificando o texto-fonte a partir dos discursos do lobo, do homem e do carneiro que podem relativizar verdades e desconstruir conceitos já consolidados no repertório cultural dos leitores.

Para dar conta de boa compreensão do que foi dito, proponho uma análise pormenorizada sobre alguns elementos semióticos e pragmáticos de quatro dessas histórias.

Comecemos pela primeira história de insônia, quando a autora já nos apresenta a velha prática de contar carneiros para adormecer. Com insônia, o homem começa a contar carneiros pulando uma cerca. Vejamos a história:

\section{PRIMEIRA HISTÓRIA DE INSÔNIA}

Porque o sono se recusa a emantá-lo na cama, um homem começa a contar carneiros. Do que se aproveita o lobo, para deslizar sorrateiro na cena e posicionar-se, boca aberta, do outro lado da cerca (COLASSATI, 2012, p. 65).

Já de imediato, chama nossa atenção o verbo emantar, um neologismo para cumprir duas funções significativas: cobrir o homem com uma manta, associando o ato ao processo de 
imantar, prender por ímã. Ao afirmar que o sono se recusava a emantar o homem na cama, a autora nos remete ao universo da insônia, já anunciado no título do miniconto. A conjunção porque, de semântica causal, já aparece no início do miniconto de forma a apresentar, de imediato, a justificativa da decisão de contar carneiros. Mais comum nessa construção sintática, em que prevaleça a ordem indireta da oração subordinada causal com a principal, seria o uso da conjunção como. Com essa quebra de paradigma sintático, Colassanti já nos insere no incomum, dando-nos uma pista inicial de que haverá inversões inusitadas nos contos seguintes. Pode-se dizer, então, que essa conjunção vai ancorar o insólito nas histórias de insônia. Mais adiante nesse miniconto, a figura do lobo é inserida em uma narrativa também incomum. Ao contar carneiros pulando cercas para, digamos, chamar o sono, é incomum ter-se um lobo na cena, ainda mais deslizando sorrateiro e posicionando-se de boca aberta do outro lado da cerca com intenções próprias de sua cadeia alimentar. O próprio "deslizar sorrateiro" já representa a intenção do lobo em penetrar na cena sem ser percebido para realizar seu intento: comer os carneiros que pulam a cerca. Nas palavras de Darcilia, a linguagem precisa ter estratégias técnico-teóricas que sejam capazes de penetrar no espaço da semiose, formulando "caminhos de interpretação que respondam à clássica pergunta Semiótica: por que isto significa o que significa?" (SIMÕES, 2019, p. 
25). Por que o lobo, então, significa a morte, o horror? Na maioria dos contos de fadas e nas fábulas de Esopo, a figura do lobo está associada à morte de algum personagem como os porquinhos e a avó da Chapeuzinho Vermelho. Com efeito, presente no imaginário coletivo, os contos de fadas receberam muitas versões ao longo do tempo, desmistificando os terrores dos contos originais para amenizar a tensão, o medo. Nos sequentes minicontos de insônia, podemos associar a figura assustadora do lobo a um processo de cognição, em cujo esquema se apoiam os signos diversos das histórias com suas possíveis interpretações em função de suas produções e estruturações sígnicas, inserindo as narrativas em um ambiente completamente insólito. Darcilia afirma que, segundo Peirce,

os raciocínios se produzem por meio de uma mistura de signos (índices, ícones e símbolos); por isso, entender o pensamento demanda o conhecimento da variedade sígnica e das suas misturas possíveis, assim como o nascimento e a evolução dos signos. (SIMÕES, 2019, p. 29)

Proponho analisar alguns percursos mentais associados aos sentidos (visão, audição, tato, paladar e olfato) presentes nesses minicontos. Sem dúvida, essa é uma das maiores demonstrações de que as matrizes sonora, visual e verbal contribuem para a apreensão dos processos comunicativos nos textos de Colassanti. 


\section{SEGUNDA HISTÓRIA DE INSÔNIA}

O lobo insone decide contar carneiros. Mas ao ver o primeiro saltando a cerca, não resiste. Lança-se atrás dele, e o persegue até acabá-lo em sangue. Cheio o ventre, adormece saciado (COLASSANTI, 2013, p. 183).

O verbo ver e o adjetivo saciado são signos que representam os sentidos da visão e do paladar respectivamente. Com esses signos, pode-se entrever as reais intenções do lobo ao entrar nas histórias de insônia, ou seja, saciar sua fome e alimentar mais que sua fome física, mas, principalmente, seu paladar e sua necessidade de matar, própria de sua natureza. O verbo perseguir pode ser entendido como indício de todos os atos do lobo na sequência das narrativas da insônia.

Vejamos que, como foi dito no início do artigo, as tramas das narrativas insólitas de Marina Colassanti, especificamente nas treze histórias de insônia, podem confirmar as palavras de Geraldi (apud Simões, 2019, p. 93) que se "costuram" perfeitamente ao que a autora do livro de contos já antecipa em seu prólogo: as linhas que tecem os textos, metáforas marcantes em toda a obra da autora.

O texto se oferece ao leitor e nele se realiza a cada leitura, num processo dialógico cuja trama toma as pontas dos fios do bordado tecido para tecer sempre o mesmo e outro bordado, pois as mãos que agora tecem 
trazem e traçam outra história. Logo, a atividade de leitura é uma coprodução textual, que precisa ser negociada entre os "parceiros" (autor/enunciador e leitor/ enunciatário/coautor). Tal negociação é deflagrada pelas marcações linguísticoicônicas que se apresentam ao leitor como elementos mapeadores do texto, uma vez que revelam a organização de microestruturas que se combinam e constroem o tecido textual, ao mesmo tempo que ativariam esquemas mentais indispensáveis à captação dos possíveis referenciais do enunciador, associando-os (ou não) aos referenciais do leitor, construindo o que se costuma denominar como conhecimento compartilhado [...]. (SIMÕES, 2019, p. 93)

Na terceira história de insônia, a autora retira o lobo da cena e põe os carneiros a dormir no redil. "Menos um. Que para chamar o sono decide contar homens pulando a cerca." Nesse trecho, pode-se interpretar a entrada de mais uma pista do insólito por meio de elementos mapeadores capazes de ativar esquemas mentais no leitor para a captação da maior referência pretendida pelo enunciador: tudo nesses contos é ambientado num cenário absolutamente onírico, insólito, improvável. O verbo decidir, cujo sujeito é o carneiro, já representa uma iconicidade de personificação do animal. Trata-se de uma representação plástica, modelar, de uma ideia improvável. O fato de o carneiro querer contar 
homens pulando a cerca conduz o leitor a um raciocínio, a uma interpretação por contiguidade de que o homem será manipulado pelos dois animais das cenas: o lobo e o cordeiro. Há uma inversão dos papéis dos personagens, percebida por meio dos signos verbais do ponto de vista da trama textual, além da estruturação gramatical. A isso chamamos de iconicidade: a escolha do léxico, a colocação dos termos e a ordem das orações, a eleição do gênero textual, da tipologia e da diagramação das histórias curtas, entremeadas por outras, cortando a sequência das treze narrativas de mesmo tema. Esse edifício teórico de Darcilia Simões nos ajuda a interpretar os caminhos do texto de Colassanti (ou de qualquer autor), a costurar as narrativas de forma a torná-las menos subjetivas em decorrência de interpretações pessoais, perigosas em um ambiente de concurso, por exemplo.

\section{QUARTA HISTÓRIA DE INSÔNIA}

Enfurecidos com o homem que, noite após noite, Ihes impede o sono obrigando-os a saltar cercas, os carneiros invadem a cama e com cascos e dentes o adormecem para sempre.

Na quarta história de insônia, os carneiros se enfurecem com o homem que os põe a pular cerca diariamente e 
invadem a cama e "com cascos e dentes o adormecem para sempre." Percebemos, nesse trecho destacado entre aspas, um eufemismo para a morte do homem - "o adormecem para sempre". Houve uma inversão de papéis entre lobos e cordeiros. Mais uma demonstração do universo insólito dos pequenos contos. As escolhas lexicais de "enfurecidos", "obrigando-os", "invadem" e "com cascos e dentes" nos fornecem pistas indiciais de que o homem está em perigo. Esse raciocínio é conseguido por um processamento cognitivo que resulta de operações mentais iniciadas na materialidade do texto. Como afirma Fauconnier (1984, 1997), expressões linguísticas são capazes de acionar espaços mentais, responsáveis por conexões cognitivas e linguísticas das línguas naturais. Nas palavras de Darcilia:

Os espaços mentais podem ser definidos como construtos mentais necessariamente constituídos no processamento de todo e qualquer discurso-texto, a partir de pistas oferecidas pelas expressões linguísticas materializadas no texto. (SIMÕES, 2019, p. 89).

Dito isso, conseguimos mapear os textos com as pistas icônicas e indiciais que nos permitem realizar uma interpretação menos subjetiva de forma a apresentar aos nossos alunos um percurso mais seguro para realizar uma boa leitura, numa "negociação entre imagens mentais 
construídas por um enunciador e reconstruídas por um coenunciador (leitor intérprete)" (Simões, 2019, p. 91). Essas imagens mentais produzidas nas histórias de insônia são, a exemplo do que se pretende demonstrar, uma forma de tradução do signo visual em signos verbais cuja produção sígnica é capaz de construir uma entidade plástica visual, ou seja, imagética, facilmente reconhecida pelos interlocutores treinados para habilitar essa competência de enfrentamento do signo e da correta captura de suas funções e valores significativos no texto. A relação entre enunciador e enunciatário é mediada pelo código verbal em cuja plasticidade se funda o potencial icônico do texto. Quanto mais representativos forem esses signos, tanto mais será a potencialidade icônica dos textos.

Limito aqui a avaliação das narrativas insólitas dos minicontos sobre a insônia, não por ter dado como finalizado o trabalho de reconhecimento e mapeamento das pistas icônicas e indiciais de tais narrativas, mas por total falta de tempo e espaço. Deixo, no entanto, a curiosidade aguçada para quem queira conhecer melhor os contos dessa obra da Colassanti e, principalmente, quem queira adentrar no vasto campo de pesquisa e análise da Teoria da Iconicidade Verbal de Darcilia Simões. 


\section{SOBRE ESTÓRIAS ABENSONHADAS}

Como forma de ampliar o horizonte de quem queira ir mais fundo nessa análise, que nos habilita para uma boa compreensão e interpretação de textos literários, integro o artigo com o prólogo do livro Estórias Abensonhadas de Mia Couto (2012) e uma proposta de observação dos signos imanentes de aspectos estruturais para demonstrar que há uma correlação entre essas estruturas sintagmáticas e as escolhas lexicais do campo semântico-pragmático de base funcionalista capazes de fortalecer o reconhecimento da existência de iconicidade também na gramática de uma língua.

Vamos, então, ratificar o que é iconicidade com um trecho do livro "Semiótica \& Ensino: letramento pela imagem" de Simões: "Trata-se de uma propriedade semiótica fundada na plasticidade - propriedade da matéria de adquirir formas sensíveis por efeito de uma força exterior" (SIMÕES, 2017, p. 17). Simões nos ensina que esse atributo pode ser estendido ao plano abstrato graças à capacidade cognitiva do homem em compor uma fábrica de imagens mentais. A iconicidade, então, se torna uma possibilidade de raciocínio que une o concreto e o abstrato, ou seja, a iconicidade diagramática (dos eixos sintagmático e paradigmático) e iconicidade imagética 
ou metafórica. A primeira se funda na gramática como reguladora das possibilidades de arranjos sintáticos e morfológicos; a segunda decorre da capacidade de operações mentais subjetivas (plano icônico-indicial das imagens e plano icônico-simbólico das metáforas). Por ser matéria ainda árdua para o entendimento de leitores e estudiosos incipientes na área da cognição e da semiótica, proponho uma análise mais concreta do prólogo do livro de Mia Couto.

A respeito da obra desse autor, Estórias abensonhadas, posso adiantar que, sem o percurso semiótico, mais especificamente da TIV, não compreenderíamos a obra na profundidade com que o autor mergulhou nela. Para dar conta de entendermos bem sua perspectiva, é preciso compreender as metáforas e metonímias já apresentadas no prólogo.

Estas estórias foram escritas depois da guerra. Por incontáveis anos as armas tinham vertido luto no chão de Moçambique. Estes textos me surgiram entre as margens da mágoa e da esperança. Depois da guerra, pensava eu, restavam apenas cinzas, destroços sem íntimo. Tudo pesando, definitivo e sem reparo. Hoje sei que não é verdade. Onde restou o homem sobreviveu semente, sonho a engravidar o tempo. Esse sonho se ocultou no mais inacessível de nós, lá onde a violência não podia golpear, 
lá onde a barbárie não tinha acesso. Em todo este tempo, a terra guardou, inteiras, as suas vozes. Quando se lhes impôs o silêncio elas mudaram de mundo. No escuro permaneceram lunares. Estas estórias falam desse território onde nos vamos refazendo e vamos molhando de esperança o rosto da chuva, água abensonhada. Desse território onde todo homem é igual, assim: fingindo que está, sonhando que vai, inventando que volta. (COUTO, 2012, p. 7, grifo nosso)

(1) Em "as armas tinham vertido luto no chão" podemos perceber uma metonímia por contiguidade de imagens e sequência lógica de acontecimentos: armas $\rightarrow$ guerra $\rightarrow$ mortes $\rightarrow$ luto. Na sequência, os signos guerra e mortes são omitidos, levando os termos polares a uma relação metonímica: armas e luto.

(2) O adjunto adverbial no chão nos remete à imagem dos corpos dos mortos, caídos pelas lutas da guerra de Moçambique. Na sequência, lemos uma metáfora bem significativa que acaba desenhando as imagens antitéticas do texto, numa seleção lexical icônica para mágoa e esperança: "Estes textos me surgiram entre as margens da mágoa e da esperança." A palavra margens nos remete ao universo hidrográfico do território moçambicano, com os onze rios que cortam o país e dividem seus domínios com países vizinhos. O signo mágoa representa todo 
o léxico de negatividade, de morte, de dor, carregando os traços daquilo que ele representa: armas, luto, guerra, cinzas, destroços, violência, golpear, barbárie. O signo esperança, por oposição, carrega os traços de sobrevivência: sobreviveu, semente, sonho, engravidar. Nesse ponto, precisamos adentrar na Semiótica das Culturas, já que a expressão desses pensamentos de Mia Couto fornece ao leitor elementos para uma investigação mais produtiva dessa relação entre os signos e seus usuários. Da mesma forma, esse levantamento dos signos e sua representatividade, da relação entre significantes e significados, só pode ser perfeitamente compreendido com um terceiro elemento da representatividade do signo, o interpretante dinâmico, ou seja, aquilo que é imediato ao contexto de produção textual. É assim que o enunciador, nesse prólogo, nos apresenta signos que só se referendam a partir do conjunto de saberes compartilhados, como o conhecimento da hidrografia de Moçambique e do que motivou a guerra no país.

Aprofundando, temos que a unidade sígnica constituída, para Peirce, é triádica e, por isso, necessita da cooperação das três instâncias: o signo, o objeto e o interpretante. Essa obra é um exemplário completo que põe à prova toda a teoria 
da iconicidade verbal. O interpretante é a base da semiose no contexto da guerra de Moçambique. Podemos dizer que é o conjunto das funções-valores que aquela comunidade discursiva construiu a partir de seus usos e costumes, o que nos ajuda a interpretar os fatos e os fenômenos que ocorrem em seu âmbito. Dessa forma, pode-se entender que a semiotização dos objetos analisados, como "luto", "mágoa", "destroços", "armas" de um lado ou "esperança", "semente", "sonho", "engravidar" de outro, pode auxiliar a Linguística (seja textual ou cognitiva) a estudar os possíveis sentidos captados pelo enunciador com base na linguagem verbal. Além da Linguística, concorre para o entendimento dos meandros desse texto a Filosofia, com a base da lógica do pensamento. Assim é que a Filosofia da Linguagem, como afirma Simões (2019):

Se incumbe da compreensão e interpretação dos processos comunicativos e de suas estratégias usados com fins de negociação de sentidos entre os participantes da comunidade em questão, buscando ampliarIhes os sentidos para o âmbito do pensardizer humano. (SIMÕES, 2019, p. 39)

Além dessas possibilidades interpretativas dos signos no prólogo de Estórias abensonhadas, temos de observar que todas as narrativas vão-se apoiar em antíteses como já 
nos antecipa o autor: silêncio e vozes, mágoa e esperança, luto e semente, cinzas e sonho. A mudança de mundo a que se refere o enunciado é o novo território em que o povo moçambicano refez suas vidas ao "molhar de esperança o rosto da chuva" a que Mia couto chama de águas abensonhadas, usando o neologismo por amálgama lexical entre os signos abençoadas e sonhadas. A água da chuva representa o brotar da semente, das vozes diante da luta, a cura da impossibilidade de falar, o cessar do silêncio político e social do povo africano. Esse sentimento é profundo como tem de estar a semente para que brote, e, segundo o autor, lugar "onde a violência não podia golpear". Nesse ponto encontramos interseção com o início do texto em prólogo: "as armas tinham vertido luto no chão de Moçambique." Interseção por antítese entre a imagem das mortes na superfície da terra e a semente de esperança no profundo da terra que representa o homem, onde os golpes não podiam alcançar. A terra é o próprio homem na compreensão do autor.

Fecho meu artigo com a certeza de que não há mais espaço para uma boa interpretação de texto literário sem a intervenção da Semiótica, particularmente da TIV. Cada texto que leio, estudo e mapeio, traz a certeza de estar 
enveredando cada vez mais denso no caminho da melhor análise de signos complexos. Para dar fim às minhas palavras, não poderia deixar de chamar aquela que inspirou cada estudo, cada palavra aqui apresentada.

Isso posto, reitera-se a complexidade do signo verbal e a necessidade de desenvolverem-se métodos de análise que, de alguma forma, facilitem a identificação de tais signos nos discursos-textos, de modo que a comunicação verbal se realize de forma mais efetiva. Tendo isso em conta, vimos buscando com a teoria da iconicidade verbal desenvolver, no mínimo, um método de análise desse signo tão complexo. (SIMÕES, 2019, p. 51)

\section{REFERÊNCIAS}

COLASSANTI, Marina. Hora de alimentar serpentes. São Paulo: Global, 2013.

COUTO, Mia. Estórias abensonhadas. São Paulo: Companhia das Letras, 2012. Edição do Kindle.

FAUCONNIER, Gilles. Espaces mentaux: aspects de la constrution du sens dans les dans les langues naturelless. Paris: Les Editions de Minuit, 1984. GERALDI, João Wanderley. O ensino da unidade na diversidade linguísticocultural. In: GERALDI, João Wanderley. Linguagem e ensino: Exercícios de militância e divulgação. Campinas, São Paulo: ALB/ Mercado das Letras, 1997, p. 49-64.

SIMÕES, Darcilia. Semiótica e ensino: letramento pela imagem. Rio de Janeiro: Dialogarts, 2017.

SIMÕES, Darcilia. Para uma teoria da iconicidade verbal. Campinas, São Paulo: Pontes Editores, 2019. 
Rosane Reis de Oliveira tem mestrado (Uma abordagem crítica sobre as questões de concordância nas provas de concursos públicos - 2009) e doutorado (Semiótica e ensino: competências e habilidades para expressão em língua portuguesa - 2014) em Letras pela Universidade do Estado do Rio de Janeiro, ambos com orientação de Darcilia Marindir Pinto Simões. Membro do SELEPROT/UERJ (Grupo de pesquisa em Semiótica, Leitura e Produção de Textos, presidido pela Doutora Darcilia Simões); membro da AILP (Associação Internacional de Linguística do Português). Professora do Rosane Reis Cursos e Mentorias Acadêmicas. 